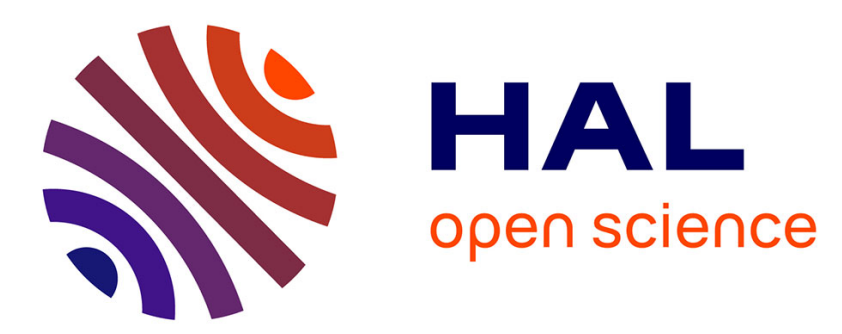

\title{
How to assess depth-of-field extension strategies applied to single-molecule super-resolution microscopes?
}

Olivier Lévêque, Caroline Kulcsár, Antony Lee, Pierre Bon, Laurent Cognet, François Goudail

\section{- To cite this version:}

Olivier Lévêque, Caroline Kulcsár, Antony Lee, Pierre Bon, Laurent Cognet, et al.. How to assess depth-of-field extension strategies applied to single-molecule super-resolution microscopes?. Computational Optical Sensing and Imaging, Jul 2021, Washington, United States. pp.CF4B.5, 10.1364/COSI.2021.CF4B.5 . hal-03417511

\section{HAL Id: hal-03417511 \\ https://hal.science/hal-03417511}

Submitted on 5 Nov 2021

HAL is a multi-disciplinary open access archive for the deposit and dissemination of scientific research documents, whether they are published or not. The documents may come from teaching and research institutions in France or abroad, or from public or private research centers.
L'archive ouverte pluridisciplinaire HAL, est destinée au dépôt et à la diffusion de documents scientifiques de niveau recherche, publiés ou non, émanant des établissements d'enseignement et de recherche français ou étrangers, des laboratoires publics ou privés. 


\title{
How to assess depth-of-field extension strategies applied to single-molecule super-resolution microscopes?
}

\author{
Olivier Lévêque ${ }^{1, *}$, Caroline Kulcsár ${ }^{1}$, Antony Lee ${ }^{2,3}$, Pierre Bon $^{2,3}$, \\ Laurent Cognet ${ }^{2,3}$ and François Goudail ${ }^{1}$ \\ ${ }^{1}$ Université Paris-Saclay, Institut d'Optique Graduate School, CNRS, Laboratoire Charles Fabry, 91127, \\ Palaiseau, France. \\ ${ }^{2}$ Université de Bordeaux, Laboratoire Photonique Numérique et Nanosciences, UMR 5298, 33400, Talence, \\ France. \\ ${ }^{3}$ Institut d'Optique \& CNRS, LP2N UMR 5298, 33400, Talence, France. \\ *olivier.leveque@institutoptique.fr
}

\begin{abstract}
Phase masks used to extend the depth-of-field (DoF) of localization microscopes are often designed to increase localization accuracy despite a loss in detection probability. We propose a method to optimize DoF extended single-molecule localization techniques taking into account the trade-off between detection probability and localization accuracy. (c) 2021 The Author(s)
\end{abstract}

\section{Context}

Super-resolution microscopy resolves biological subcellular structures beyond the diffraction limit. For instance, using photo-activated localization microscopy (PALM), lateral resolution of 2 to $\sim 25 \mathrm{~nm}$ has been achieved by localizing individual fluorophore positions [1]. To maximize lateral resolution, the microscope objective must have very high numerical aperture, which considerably limits the depth-of-field (DoF) of this imaging technique and therefore the depth of exploration with which a biological sample can be probed. Indeed, in many applications, the region of interest may not be confined within the natural DoF range of the microscope objective and it is necessary to extend the DoF of the imaging system beyond this limit.

\section{Extending depth-of-field using a phase mask}

Several works have demonstrated that placing a well-designed phase mask in the Fourier plane of a localization microscope can significantly increase its $\operatorname{DoF}[2,3]$. We have recently proposed an easy-to-manufacture annular binary phase mask to improve the 2D-localization performance over a wide defocus range [4]. This type of mask is based on concentric rings implementing phase modulation of alternatively 0 and $\pi$ radians at a nominal wavelength, and is optimized according to the Cramér-Rao bound (CRB) as a localization precision criterion. We have represented, on the top of Fig. 1.a, the variation with defocus of the point spread function (PSF) profile of a microscope equipped with this mask. In this graph, the parameter $\psi$ represents the the optical path difference between the focused and defocused spherical wavefronts at the edge of the pupil $[5,6]$ and is used as a reduced parameter to quantify defocus. We observe that this mask modifies the PSF in such a way that the lateral localization precision becomes quasi-invariant along the optical axis. This is confirmed by Fig. 1.b, which displays the normalized 2D-localization performances of a microscope without mask (blue dotted line) and with this phase mask (red dashed line). It is observed that using this mask significantly improves the localization of out-of-focus fluorophores to the expense of a loss of localization precision in the focal plane (e.i. $\psi=0)$.

\section{Trade-off between detection probability and localization accuracy}

However, the presence of a phase mask provokes a spreading of the PSF, which strongly affects the fluorophore pre-detection step that always precedes application of the super-localization estimator. We quantify the loss of detection probability induced by an optimal phase mask with the detection signal-to-noise ratio, that we denote $\mathrm{SNR}_{\mathrm{Q}}$. The pre-detection capacity is an increasing function of this parameter. We have represented the $\mathrm{SNR}_{\mathrm{Q}}$ as a function of the defocus parameter in Fig. 1.c. The red dashed line corresponds to the mask optimized with the localization criterion. We notice that the $\mathrm{SNR}_{\mathrm{Q}}$ value drops for $\psi=0$. In other words, the probability of detection of fluorophore in the focal plane decreases drastically by using a phase mask optimized with a localization criterion. Hence, when optimizing a DoF extending phase mask, it is of utmost importance to take into account probability 


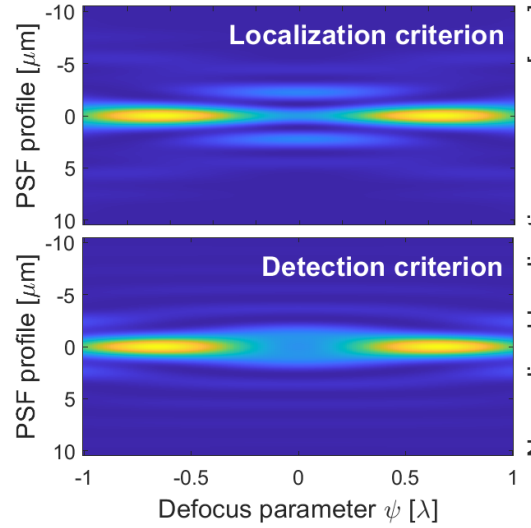

(a)

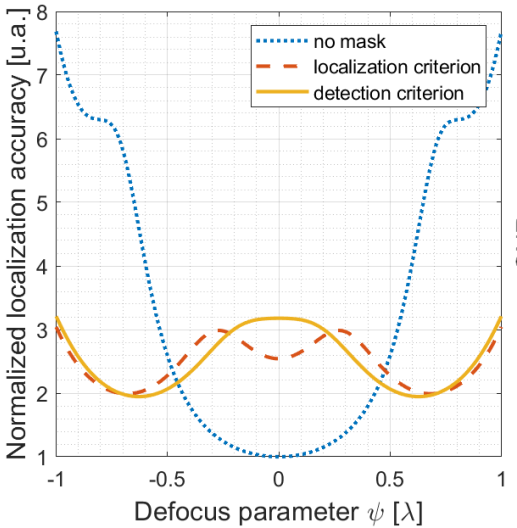

(b)

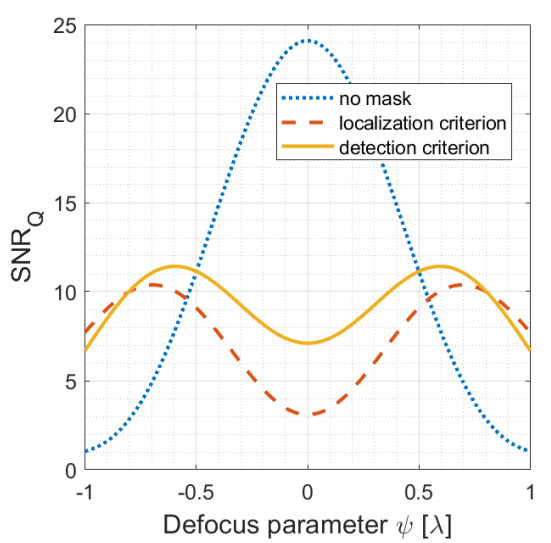

(c)

Fig. 1. (a) Variation of the transverse profile of the PSF as a function of the defocus when the microscope is equipped with a mask optimized with localization criterion or detection criterion. (b) 2D-localization accuracy without mask (blue dotted line), with optimized mask based on localization criterion (red dashed line) and with optimized mask based on detection criterion (yellow solid line) as a function of defocus. (c) Detection criterion evaluated for the same optical systems as a function of defocus.

of detection as well as localization precision. We have developed a methodology based on the $\mathrm{SNR}_{\mathrm{Q}}$ to optimize DoF extended localization techniques according to the trade-off between detection probability and localization accuracy. An example of result is displayed in Fig. 1 by the yellow solid lines. It shows that this new detection criterion gives rise to phase masks with better probability of detection while preserving localization precision. This methodology also allows us to perform a quantitative comparison, in terms of both localization precision and detection capacity, between the phase masks previously developed in the literature $[2,3,7]$ and the binary annular phase masks recently proposed by our team [8].

\section{Funding}

This work was supported by grants from Agence Nationale de la Recherche (ANR-18-CE09-0019-02), and the Fondation ARC pour la recherche sur le cancer (A. L.). This work has also received the support of the French research group GdR ISIS of the CNRS through the Projet de Recherche Exploratoire MASK.

\section{References}

1. E. Betzig, G. H. Patterson, R. Sougrat, O. W. Lindwasser, S. Olenych, J. S. Bonifacino, M. W. Davidson, J. LippincottSchwartz, and H. F. Hess, "Imaging Intracellular Fluorescent Proteins at Nanometer Resolution," Science, vol. 313, no. 5793, pp. 1642-1645, 2006.

2. S. R. P. Pavani and R. Piestun, "Three dimensional tracking of fluorescent microparticles using a photon-limited doublehelix response system," Opt. Express, vol. 16, pp. 22048-22057, Dec 2008.

3. Y. Shechtman, S. J. Sahl, A. S. Backer, and W. E. Moerner, "Optimal Point Spread Function Design for 3D Imaging," Phys. Rev. Lett., vol. 113, p. 133902, Sep 2014.

4. O. Lévêque, C. Kulcsár, A. Lee, H. Sauer, A. Aleksanyan, P. Bon, L. Cognet, and F. Goudail, "Co-designed annular binary phase masks for depth-of-field extension in single-molecule localization microscopy," Opt. Express, vol. 28, pp. 32426-32446, Oct 2020.

5. M. Born, E. Wolf, A. B. Bhatia, P. C. Clemmow, D. Gabor, A. R. Stokes, A. M. Taylor, P. A. Wayman, and W. L. Wilcock, Principles of Optics: Electromagnetic Theory of Propagation, Interference and Diffraction of Light. Cambridge University Press, 7th ed., 1999.

6. F. Aguet, Super-Resolution Fluorescence Microscopy Based on Physical Models. Theses, École polytechnique fédérale de Lausanne, May 2009.

7. S. Abrahamsson, S. Usawa, and M. Gustafsson, "A new approach to extended focus for high-speed high-resolution biological microscopy," in Three-Dimensional and Multidimensional Microscopy: Image Acquisition and Processing XIII (J.-A. Conchello, C. J. Cogswell, and T. Wilson, eds.), vol. 6090, pp. 128 - 135, International Society for Optics and Photonics, SPIE, 2006.

8. O. Lévêque, C. Kulcsár, H. Sauer, A. Lee, P. Bon, L. Cognet, and F. Goudail, "Can phase masks extend depth-of-field in localization microscopy?," in Unconventional Optical Imaging II (C. Fournier, M. P. Georges, and G. Popescu, eds.), vol. 11351, International Society for Optics and Photonics, SPIE, 2020. 